\title{
Optimization of the Fermentation Process of Actinomycete Strain Hhs.015
}

\author{
Xinxuan Wang, Lili Huang, Zhensheng Kang, Heinrich Buchenauer, and Xiaoning Gao
}

College of Plant Protection and Shaanxi Key Laboratory of Molecular Biology for Agriculture, Northwest A \& F University, Yangling 712100, China

Correspondence should be addressed to Lili Huang, huanglili1@hotmail.com

Received 25 October 2009; Revised 28 February 2010; Accepted 11 March 2010

Academic Editor: Elvira Gonzalez De Mejia

Copyright ( 92010 Xinxuan Wang et al. This is an open access article distributed under the Creative Commons Attribution License, which permits unrestricted use, distribution, and reproduction in any medium, provided the original work is properly cited.

Strain Hhs. $015^{\mathrm{T}}$ (Saccharothrix yanglingensis sp. nov.), an antagonistic endophytic Saccharothrix actinomycete isolated from roots of cucumber plants, exhibited a broad antimicrobial spectrum in vitro and was active as a biocontrol against plant diseases in field trials. The SSY medium was used for production of antimicrobial metabolites by strain $\mathrm{Hhs} .015^{\mathrm{T}}$. However, this medium is too expensive for large-scale production. In this study, an alternative culture medium, based on agricultural waste products (e.g., apple pomace), was optimized. The results showed that the alternative medium contained $15 \mathrm{~g}$ apple pomace, $4 \mathrm{~g}$ rapeseed meal, $0.1 \mathrm{~g} \mathrm{KH}_{2} \mathrm{PO}_{4}$, and $0.6 \mathrm{~g} \mathrm{MgSO}_{4} \cdot 7 \mathrm{H}_{2} \mathrm{O}$ in $1 \mathrm{~L}$ distilled water. This medium reduced the material costs by $91.5 \%$ compared to SSY medium. Response surface methodology (RSM) was used to investigate the influence of environmental variables on production of compounds of antimicrobial metabolites. The optimal conditions achieved were initial $\mathrm{pH} 7.0$, medium volume of $90 \mathrm{~mL}$ in $250 \mathrm{~mL}$ flasks, rotary speed of $100 \mathrm{rpm}$, temperature $25^{\circ} \mathrm{C}$, and inoculation volume of $15.8 \%$. The antimicrobial activity was increased by $20 \%$ by optimizing the environmental parameters. The results obtained allow an efficient production of components with antimicrobial activity by strain $\mathrm{Hhs} .015^{\mathrm{T}}$ on a large scale at low costs.

\section{Introduction}

In recent years, the increasing prevalence of infectious diseases resistant to chemotherapy has caused an urgent need to discover and develop new antibiotics. In this context, rare actinomycetes appear as a promising source of new antibacterial and antifungal compounds. Strain Hhs. $015^{\mathrm{T}}$, isolated from roots of cucumber plants, belongs to Saccharothrix actinomycete $[1,2]$. The isolate showed a broad antimicrobial spectrum in vitro against plant pathogenic (e.g., Valsa ceratosperma and Phytophthora capsici) and nonplant pathogenic fungi, for example, Candida vulgaris [3]. In field experiments, fermentation supernatant of Hhs. $015^{\mathrm{T}}$ showed effective biocontrol to tomato leaf mould caused by Fulvia fulva [4] and apple tree valsa canker caused by Valsa ceratosperma [5]. Up to date, many bioactive secondary metabolites have been reported from cultures of Saccharothrix. These include for instance, tetrazomine [6], mutactimycin [7], and dithiolopyrroloe antibiotics [8].
These metabolites are characterised by diverse chemical structures and may be suitable because of their wide range of activity in agriculture to control fungal diseases in cultivated plants and domestic animals.

Production of secondary metabolites by microorganisms differs qualitatively and quantitatively depending on the strains and species of microorganisms used as well as on their nutritional and cultural conditions [9]. And as fermentation moves into lower-value, higher-volume substrates, it becomes necessary to maximize the efficiency and minimize costs by using waste by-products to complete effectively with traditional high-value, low-volume compounds [10].

In recent years, more and more attention was paid to agricultural pomaces such as apple pomace, wheat/rice bran, corn steep liquor, and peanut meal, for their use as raw materials in the production of high value products [11-13]. Crop pomaces are annually renewable sources of energy. Approximately 3.5 billion tons of agricultural pomaces are produced per annum in the world. But utilization of these 
pomaces was limited due to low protein content and poor digestibility [14]. Studies on optimization of the production of antimicrobial active compounds using agricultural pomaces have been reported comparatively seldom.

The objective of the present study was to produce an alternate culture medium using agricultural waste as medium component and optimize fermentation conditions of the strain Hhs. $015^{\mathrm{T}}$ in order to greatly reduce the production cost and improve the formation of components with antimicrobial activity.

\section{Materials and Methods}

2.1. Culture Media. SSY liquid medium consisted of: $20 \mathrm{~g}$ soybean powder, $10 \mathrm{~g}$ sucrose, $5 \mathrm{~g}$ soluble starch, $2 \mathrm{~g}$ yeast extract, $2 \mathrm{~g}$ protease peptone, $2 \mathrm{~g} \mathrm{NaCl}, 1 \mathrm{~g} \mathrm{CaCO}_{3}, 0.5 \mathrm{~g}$ $\mathrm{MgSO}_{4} \cdot 7 \mathrm{H}_{2} \mathrm{O}, 0.5 \mathrm{~g} \mathrm{KH} \mathrm{KO}_{4}$, and $1 \mathrm{~L}$ double distilled (dd) water. SSY solid medium was prepared by adding $10 \mathrm{~g}$ agar to the liquid medium. In addition, the following media were used: PDA (200 g potato, $20 \mathrm{~g}$ dextrose, and $10 \mathrm{~g}$ agar in $1 \mathrm{~L}$ dd water), and PD (200g potato and $20 \mathrm{~g}$ dextrose in $1 \mathrm{~L}$ dd water). All cultural media, plates, and flasks used in the experiments were autoclaved at $121^{\circ} \mathrm{C}$ for 30 minutes.

2.2. Microorganisms and Culture Conditions. Strain Hhs. $015^{\mathrm{T}}$ was kept on SSY solid medium at $4^{\circ} \mathrm{C}$. For spore production, the strain was transferred to SSY solid medium plates and incubated for 7 days in darkness at $28^{\circ} \mathrm{C}$. The spores produced on the plates were used for inoculation of the liquid fermentation media. Two spore cakes (diameter $4 \mathrm{~mm}$ ) of strain Hhs. $015^{\mathrm{T}}$ were prepared to inoculate a 250-mL flask containing $50 \mathrm{~mL}$ SSY medium. The flasks were incubated at $28^{\circ} \mathrm{C}$ on a rotary shaker at $150 \mathrm{rpm}$ for 48 hours in darkness. For optimization of an alternative culture medium, submerged fermentation was carried out in 250-mL flasks containing $50 \mathrm{~mL}$ different test fermentation media. These flasks were inoculated with $10 \%(\mathrm{v} / \mathrm{v})$ of the spore culture and incubated in darkness at $28^{\circ} \mathrm{C}$ on a rotary shaker at $150 \mathrm{rpm}$ for $5 \mathrm{~d}$. For optimization of fermentation conditions, the experiment was carried out according to the experimental design. After fermentation, all of the test fermentation broths were centrifuged at $11,086 \times \mathrm{g}$ for 10 minutes; the supernatants (test samples) were used to evaluate the antimicrobial activity.

Candida vulgaris as the target microbe was kept on PDA medium at $4^{\circ} \mathrm{C}$ and was cultivated in $\mathrm{PD}$ liquid culture medium in darkness at $28^{\circ} \mathrm{C}$ on a rotary shaker at $150 \mathrm{rpm}$ for 2 days. Then, C. vulgaris culture medium $\left(10^{8}-10^{9}\right.$ spores $\left./ \mathrm{mL}\right)$ was kept at $4^{\circ} \mathrm{C}$ for the assay of the antimicrobial activity in the fermentation supernatant produced by Hhs. $015^{\mathrm{T}}$.

\subsection{Testing the Effect of Carbon, Nitrogen, and Microelement} Sources in the Medium on the Production of Antimicrobial Active Components. In order to investigate the effect of the carbon and nitrogen sources on the antimicrobial activity produced by strain Hhs. $015^{\mathrm{T}}$, SSY medium was used as a basal medium for the following optimization studies. Various single and complex carbon or nitrogen sources (Tables 1 and 2) were used to replace the carbon and nitrogen sources in the SSY medium, while all other components were kept constant.

In the selection of proper microelements, all of the microelements in SSY medium were replaced by one microelement at different concentrations. The antimicrobial activity was evaluated by measurement of inhibition zones of the target organism after 24 hours of incubation at $30^{\circ} \mathrm{C}$ (see Section 2.5). The prices of the different carbon and nitrogen sources are listed in Tables 1 and 2.

2.4. Experimental Design and Optimization. The alternative culture media were optimized according to orthogonal tests. In the orthogonal tests, an $\mathrm{L}_{16} 4^{5}$ experimental design was employed for 4 independent variables each at 4 levels. A total of 16 experiments were carried out simultaneously, each experiment with three replicates. The variables involved in the study and their concentrations were given in Table 3.

The optimization of the fermentation conditions was carried out according to the central composite tool (CCD) of RSM (Response Surface Methodology) using MINITAB 14 software (Minitab Inc., 2003) for selected five environmental factor parameters $[15,16]$. The crucial factors involved in the study and their concentrations are given in Table 4. A total of 32 experiments were carried out simultaneously (Table 5), with experiments 2, 4, 6, 8, and 17 as five replicates of the central point. Relative effects of two variables on response were identified from contour plots. An optimum value of the variables for maximum antimicrobial activity was determined by response optimizer tool of the software.

2.5. Assay for Antimicrobial Activity. The antibacterial assay was carried out using the Oxford Cup method in 20$\mathrm{cm}$-diameter Petri dishes. After autoclaving, $100 \mathrm{~mL}$ PDA medium were cooled to $40-50^{\circ} \mathrm{C}$, and $1 \%(\mathrm{v} / \mathrm{v})$ of the $C$. vulgaris suspension $\left(10^{8}-10^{9}\right.$ spores $\left./ \mathrm{mL}\right)$ was added to the PDA medium. After the medium in the Petri dishes solidified, the autoclaved Oxford cups were put onto the medium surface and $200 \mu \mathrm{L}$ of the testing samples (supernatants) were added into the cups. One Petri dish was one replicate. The antimicrobial activity was evaluated by measuring the diameter of translucent inhibition zones after incubating the dishes 24 hours at $30^{\circ} \mathrm{C}$.

2.6. Data Calculation and Analysis. The data from the orthogonal tests were analyzed by SAS software (Stat Soft, Inc., Tulsa, USA). The optimum value of the variables for the maximum antimicrobial activity was obtained by range analysis (Table 6). Range of every variable can roughly explain the effect of every variable on the antimicrobial activity. The range of every variable was calculated according to the following equation:

$$
\begin{gathered}
\bar{X}_{i j}=\frac{X_{i j}}{n}, \quad n=4, \quad j=1,2,3,4, \\
R_{i}=\bar{X}_{i j \max }-\bar{X}_{i j \min }, \quad i=1,2,3,4,
\end{gathered}
$$


TABLE 1: Effect of various carbon sources replacing starch and sucrose in SSY medium on antimicrobial activity of strain Hhs.015 ${ }^{\mathrm{T}}$ to Candida vulgaris incubated 24 hours at $30^{\circ} \mathrm{C}$ on PDA medium.

\begin{tabular}{|c|c|c|c|c|}
\hline Carbon sources & $\begin{array}{c}\text { Diameter of } \\
\text { inhibition zones } \\
(\mathrm{mm})\end{array}$ & $\begin{array}{c}\text { Price } \\
(\mathrm{RMB} / \mathrm{Kg})\end{array}$ & supplier & $\begin{array}{c}\text { Contents of } \\
\text { carbon } \%\end{array}$ \\
\hline Glucose & $18.65 \mathrm{a}$ & 14 & Fuchen Chemical Company, Tianjin & $<99.2$ \\
\hline White sugar & $18.33 \mathrm{a}$ & 4.5 & Farmer's Market, Yangling, Shaanxi & 90.25 \\
\hline Brown sugar & $17.86 \mathrm{ab}$ & 5 & Farmer's Market, Yangling, Shaanxi & 80.32 \\
\hline Apple pomace (hydrolyzate) & $17.45 \mathrm{ab}$ & 0.6 & Juice factory, Qianxian, Shaanxi & 15.08 \\
\hline Starch & $16.21 \mathrm{ab}$ & 28 & Fuchen Chemical Company, Tianjin & $<98.5$ \\
\hline Control (Starch+ sucrose) & $15.28 \mathrm{bc}$ & 29 & Fuchen Chemical Company, Tianjin & $<98.5$ \\
\hline Bran & $13.15 \mathrm{c}$ & 1.2 & Farmer's Market, Yangling, Shaanxi & 16.23 \\
\hline Black & $7.78 \mathrm{~d}$ & 0 & & \\
\hline Vinegar residue (hydrolyzate) & $7.75 \mathrm{~d}$ & 0.6 & Farmer's Market, Yangling, Shaanxi & 10.15 \\
\hline
\end{tabular}

Note: Inhibition zones with the same letter showed no significant difference analyzed by SAS statistics systems. The portion of carbon sources was about $1.5 \%$ $(\mathrm{w} / \mathrm{v})$. The control medium was the SSY medium. The Black had no starch and sucrose in SSY medium.

TABLE 2: Effect of various nitrogen sources replacing soybean powder, yeast extract, and protease peptone in SSY medium on antimicrobial activity of strain Hhs. $015^{\mathrm{T}}$ to Candida vulgaris incubated 24 hours at $30^{\circ} \mathrm{C}$ on PDA medium.

\begin{tabular}{|c|c|c|c|c|}
\hline Nitrogen sources & $\begin{array}{c}\text { Diameter of } \\
\text { zones of } \\
\text { inhibition }(\mathrm{mm})\end{array}$ & $\begin{array}{c}\text { Price } \\
(\mathrm{RMB} / \mathrm{Kg})\end{array}$ & supplier & $\begin{array}{l}\text { Contents of } \\
\text { nitrogen }\end{array}$ \\
\hline $\begin{array}{l}\text { Rapeseed meal } \\
\text { (hydrolyzate) }\end{array}$ & $19.59 \mathrm{a}$ & 0.6 & Farmer's market, Yangling Shaanxi & $1.67 \%$ \\
\hline$\left(\mathrm{NH}_{4}\right)_{2} \mathrm{HPO}_{4}$ & $17.32 \mathrm{ab}$ & 30 & Fuchen Chemical Company, Tian Jin & $20.31 \%$ \\
\hline $\begin{array}{l}\text { Cotton dregs } \\
\text { (hydrolyzate) }\end{array}$ & $17.20 \mathrm{ab}$ & 0.6 & Farmer's market, Yangling Shaanxi & $3.1 \%$ \\
\hline $\begin{array}{l}\text { Control (soybean } \\
\text { powder }+ \text { yeast extract }+ \\
\text { protease peptone) }\end{array}$ & $17.05 \mathrm{ab}$ & 245 & Fuchen Chemical Company, Tian Jin & $10 \%$ \\
\hline$\left(\mathrm{NH}_{4}\right)_{2} \mathrm{SO}_{4}$ & $16.75 \mathrm{ab}$ & 32 & Fuchen Chemical Company, Tian Jin & $17.92 \%$ \\
\hline Fish meal (hydrolyzate) & $16.91 \mathrm{ab}$ & 6 & Farmer's market, Yangling Shaanxi & $3.33 \%$ \\
\hline Black & $16.49 \mathrm{ab}$ & 0 & & 0 \\
\hline Urea & $15.57 \mathrm{bc}$ & 2 & Fuchen Chemical Company, Tian Jin & $35.84 \%$ \\
\hline $\mathrm{NaNO}_{3}$ & $13.11 \mathrm{bc}$ & 22 & Fuchen Chemical Company, Tian Jin & $17.92 \%$ \\
\hline $\mathrm{NH}_{4} \mathrm{NO}_{3}$ & $0.00 \mathrm{~d}$ & 28 & Fuchen Chemical Company, Tian Jin & $35.84 \%$ \\
\hline
\end{tabular}

Note: Inhibition zones with the same letter showed no significant difference analyzed by SAS statistics systems. 1.5\% (w/v) of apple pomace was used as the carbon source replacing starch and sucrose in SSY medium except the control. The portion of nitrogen sources was about $0.7 \%$ (w/v). The control medium was the SSY medium. The Black: without soybean powder, yeast extract, and protease peptone in SSY medium

where $\bar{X}_{i j}$ is the average value of the $j$ level of one variable in line, $i, n$ is the number of replications of every level of one variable in one line. $R_{i}$ is the difference of the maximum and the minor average value of all of the levels of one variable in line $i$.

The experimental results of RSM were fitted with the response surface regression procedure. In developing the regression equation, the test variables were coded according to the equation:

$$
x_{i}=\frac{\left(X_{i}-\bar{X}_{i}\right)}{X_{i}}, \quad i=1,2,3, \ldots, k,
$$

where $\mathrm{x}_{i}$ was the independent variable coded value, $X_{i}$ was the independent variable real value, $X_{i}$ was the independent variable real value on the centre point, and $\bar{X}_{i}$ was the step change value. The response variable (antimicrobial activity unit) was fitted by a second-order model in order to correlate the response variable to the independent variables. The general form of the second degree of polynomial equation is: $Y=b_{0}+\sum_{i} b_{i} x_{i}+\sum_{i} \sum_{j} b_{i j} x_{i} x_{j}+\sum b_{i i} x_{i}^{2}$, where $Y$ was the measured response, $b_{0}$ was the intercept term, $b_{i}, b_{i j}$, and $b_{i i}$ were the measures of the effects of variables $x_{i}, x_{i} x_{j}$, and $x_{i}^{2}$, respectively. The variable $x_{i} x_{j}$ represents the first-order interaction between $x_{i}$ and $x_{j}(i<j)$.

The statistical analysis of the model was performed in the form of analysis of variance (ANOVA). This analysis included the Fisher's $F$-test (overall model significance), its associated probability $P(F)$, correlation coefficient $R$, and determination coefficient $R^{2}$ that measured the goodness of 
TABLE 3: Experimental range and levels of the independent variables of orthogonal design for the optimization of strain Hhs. $015^{\mathrm{T}}$ alternative cultural medium.

\begin{tabular}{lccccc}
\hline Variable & Parameter & \multicolumn{4}{c}{ Range and levels } \\
\hline$A$ & Apple pomace & $1.5 \%$ & $2.0 \%$ & $2.5 \%$ & $3.0 \%$ \\
$B$ & Rapeseed meal & $0.1 \%$ & $0.2 \%$ & $0.3 \%$ & $0.4 \%$ \\
$C$ & $\mathrm{MgSO}_{4} \cdot 7 \mathrm{H}_{2} \mathrm{O}$ & $0.06 \%$ & $0.07 \%$ & $0.08 \%$ & $0.09 \%$ \\
$D$ & $\mathrm{KH}_{2} \mathrm{PO}_{4}$ & $0.01 \%$ & $0.02 \%$ & $0.03 \%$ & $0.04 \%$ \\
\hline
\end{tabular}

TABLE 4: Variances and levels of the optimization of strain Hhs. $015^{\mathrm{T}}$ fermentation conditions using Response Surface Methodology.

\begin{tabular}{lcccccc}
\hline Variables & Parameter & -2 & -1 & 0 & 1 & 2 \\
\hline $\mathrm{pH}$ & $X_{1}$ & 2.0 & 4.5 & 7.0 & 9.5 & 12 \\
Medium volume $(\mathrm{mL})$ & $X_{2}$ & 30 & 60 & 90 & 120 & 150 \\
Rotary speed $(\mathrm{rev} / \mathrm{min})$ & $X_{3}$ & 0 & 50 & 100 & 150 & 200 \\
Temperature $\left({ }^{\circ} \mathrm{C}\right)$ & $X_{4}$ & 15 & 20 & 25 & 30 & 35 \\
Inoculation volume $(\%)$ & $X_{5}$ & 8 & 11 & 14 & 17 & 20 \\
\hline
\end{tabular}

Note: $x_{i}=$ coded value of the variable $X_{i} . X_{1}=(\mathrm{pH}-7) / 2.5 ; X_{2}=($ Medium volume -90$) / 30 ; X_{3}=($ Rotary speed -100$) / 50 ; X_{4}=($ Temperature -25$) / 5$; $X_{5}=($ Inoculation volume -14$) / 3$.

fit of the regression model. The analysis also included the Student's $t$-value for the estimated coefficients and associated probabilities, $P(t)$. For each variable, the quadratic models were represented as contour plots.

\section{Results}

3.1. Screening the Components in the Alternative Culture Medium for Fermentation of Strain Hhs.015 ${ }^{T}$. The results indicated that the carbon sources obviously affected the synthesis of substances with antimicrobial activity by strain Hhs.015 ${ }^{\mathrm{T}}$ (Table 1). Among the various carbon sources tested, strain Hhs. $015^{\mathrm{T}}$ produced in the presence of glucose (18.65 mm diameter of growth inhibition zones), white sugar $(18.33 \mathrm{~mm})$, brown sugar $(17.86 \mathrm{~mm})$, apple pomace $(17.45 \mathrm{~mm})$, and starch $(16.21 \mathrm{~mm})$ greater growth inhibition zones than in the control medium $(15.28 \mathrm{~mm})$. Statistical analysis indicated that the growth inhibition zones were significantly different from the control for glucose and white sugar, while the growth inhibition zones were not significantly different from glucose and white sugar for apple pomace. The inhibition zones significantly differed from the control according to the statistical analysis. Significant lower antimicrobial activities were found in the vinegar residue $(7.75 \mathrm{~mm})$ as well as in black $(7.75 \mathrm{~mm})$ and bran $(13.15 \mathrm{~mm})$. Taking the costs of the raw materials into consideration, the price of apple pomace $(0.6 \mathrm{RMB} / \mathrm{Kg})$ was much lower compared with other carbon sources showing similar antimicrobial activity.

The results of the nitrogen sources showed that strain Hhs. $015^{\mathrm{T}}$ could utilize different forms both organic and inorganic nitrogen sources (Table 2). Rapeseed meal favored production of compounds with antimicrobial activity
(19.59 mm diameter of inhibition zones) but not significantly compared to the control. Also in media containing urea and $\mathrm{NaNO}_{3}$, components with low antimicrobial activity were produced; these sources were not significantly different from the control and other sources (e.g., ammonium phosphate, cotton dregs, ammonium sulfate, and fish meal). No antimicrobial activity was found in the medium with $\mathrm{NH}_{4} \mathrm{NO}_{3}$. Thus, considering the price of raw materials and the antimicrobial activity produced, apple pomace and rapeseed meal were used as carbon and nitrogen sources for further experiments.

The results showed (Figure 1) that the antimicrobial activity produced by strain $\mathrm{Hhs} .015^{\mathrm{T}}$ enhanced in the presence of $\mathrm{MgSO}_{4} \cdot 7 \mathrm{H}_{2} \mathrm{O}$ concentrations increasing from $0.05 \%$ to $0.08 \%$ and $\mathrm{KH}_{2} \mathrm{PO}_{4}$ levels increasing from 0 to $0.01 \%$, but the activity decreased while the concentrations of the other microelements increased, for example, $\mathrm{NaCl}$ and $\mathrm{CaCO}_{3}$ (Figure 1). Therefore, $\mathrm{MgSO}_{4} \cdot 7 \mathrm{H}_{2} \mathrm{O}$ and $\mathrm{KH}_{2} \mathrm{PO}_{4}$ were chosen as the microelements for further experiments.

3.2. Orthogonal Design for the Optimization of the Alternative Cultural Medium for Strain Hhs. $015^{T}$. The effects of concentrations of the components in the medium on the antimicrobial activity were further investigated by tests of orthogonal design. From the range analysis, the apple pomace as the main variable affected the antimicrobial activity, indicating that the carbon source was essential for the production of compounds with antimicrobial activity by strain Hhs. $015^{\mathrm{T}}$. From the results of the analysis of variance of orthogonal design, (Table 7) showed that each single variable had no significant effect on the antimicrobial activity $\left(F<F_{0.05}\right)$, probably because in the experiments the concentration range of every variable was defined. Finally, the optimum values of apple pomace $15 \mathrm{~g} / \mathrm{L}$, rapeseed meal $4 \mathrm{~g} / \mathrm{L}, \mathrm{KH}_{2} \mathrm{PO}_{4} 0.1 \mathrm{~g} / \mathrm{L}$, and $\mathrm{MgSO}_{4} \cdot 7 \mathrm{H}_{2} \mathrm{O} 0.6 \mathrm{~g} / \mathrm{L}$ were determined according to the range analysis (Table 6 ). The antimicrobial activity produced in the alternative culture medium was not significantly different from the SSY medium (Figure 2A, CK), while the price of the materials of $0.1836 \mathrm{RMB} / \mathrm{L}$ was drastically lower than the price of the SSY medium, 2.1624 RMB/L; thus, the price was reduced by $91.5 \%$.

3.3. Optimization of Fermentation Conditions for Strain $H h s .015^{T}$. Applying multiple regression analysis on the experimental data, the results (Table 5) of the CCD design fitted with a second-order of polynomial equation:

$$
\begin{aligned}
Y= & 15.7443+1.4375 X_{1}-1.6625 X_{2}+3.8792 X_{3} \\
& -2.0443 X_{1}^{2}-2.9743 X_{2}^{2}-2.2193 X_{3}^{2}-3.9943 X_{4}^{2} \\
& +1.5313 X_{1} X_{5}+1.5313 X_{2} X_{4},
\end{aligned}
$$

where $Y$ was the response (the antimicrobial activity units) and $X_{1}, X_{2}, X_{3}, X_{4}$, and $X_{5}$ were the coded values of the independent variables, initial $\mathrm{pH}$, medium volume in the flask, rotary speed, temperature, and inoculation volume, respectively. 
TABle 5: Experiment design and results of the optimization of strain Hhs. $015^{\mathrm{T}}$ fermentation conditions using Response Surface Methodology.

\begin{tabular}{|c|c|c|c|c|c|c|c|c|}
\hline Runs & $X_{1}$ & $X_{2}$ & $X_{3}$ & $X_{4}$ & $X_{5}$ & $\begin{array}{c}\text { Observed Value }^{\mathrm{b}} \\
(\mathrm{mm})\end{array}$ & $\begin{array}{l}\text { Predicted Value } \\
(\mathrm{mm})\end{array}$ & Residual \\
\hline 1 & 0 & 0 & 0 & -2 & 0 & 5.5 & -1.9 & 1.86 \\
\hline $2^{\mathrm{a}}$ & 0 & 0 & 0 & 0 & 0 & 15.3 & 15.7 & -0.44 \\
\hline 3 & 1 & -1 & -1 & 1 & 1 & 0.0 & 1.3 & -1.29 \\
\hline $4^{\mathrm{a}}$ & 0 & 0 & 0 & 0 & 0 & 15.8 & 15.7 & 0.06 \\
\hline 5 & 2 & 0 & 0 & 0 & 0 & 15.6 & 10.4 & 5.16 \\
\hline $6^{\mathrm{a}}$ & 0 & 0 & 0 & 0 & 0 & 17.6 & 15.7 & 1.86 \\
\hline 7 & 1 & 1 & -1 & 1 & -1 & 0.0 & 0.9 & -0.92 \\
\hline $8^{\mathrm{a}}$ & 0 & 0 & 0 & 0 & 0 & 15.7 & 15.7 & -0.04 \\
\hline 9 & -1 & 1 & 1 & 1 & -1 & 10.6 & 8.7 & 1.87 \\
\hline 10 & 1 & -1 & 1 & -1 & 1 & 15.0 & 16.8 & -1.78 \\
\hline 11 & 1 & 1 & 1 & -1 & -1 & 0.0 & 1.4 & -1.40 \\
\hline 12 & 0 & 0 & 0 & 0 & 2 & 14.4 & 14.9 & -0.49 \\
\hline 13 & 1 & 1 & 1 & 1 & 1 & 11.4 & 11.6 & -0.23 \\
\hline 14 & 1 & 1 & -1 & -1 & 1 & 0.0 & 1.4 & -1.37 \\
\hline 15 & -1 & -1 & 1 & 1 & 1 & 12.5 & 11.0 & 1.50 \\
\hline 16 & 0 & 0 & 2 & 0 & 0 & 14.2 & 14.6 & -0.43 \\
\hline $17^{\mathrm{a}}$ & 0 & 0 & 0 & 0 & 0 & 13.6 & 15.7 & -2.14 \\
\hline 18 & -2 & 0 & 0 & 0 & 0 & 0.0 & 4.7 & -4.69 \\
\hline 19 & 0 & 0 & 0 & 2 & 0 & 0.0 & 1.4 & -1.39 \\
\hline 20 & -1 & 1 & -1 & -1 & -1 & 0.0 & -0.7 & 0.73 \\
\hline 21 & 0 & 2 & 0 & 0 & 0 & 0.0 & 1.2 & -1.24 \\
\hline 22 & -1 & -1 & 1 & -1 & -1 & 7.6 & 7.3 & 0.32 \\
\hline 23 & 1 & -1 & -1 & -1 & -1 & 0.0 & 2.5 & -2.47 \\
\hline 24 & -1 & -1 & -1 & -1 & 1 & 0.0 & -0.4 & 0.36 \\
\hline 25 & -1 & 1 & -1 & 1 & 1 & 0.0 & -1.9 & 1.91 \\
\hline 26 & -1 & 1 & 1 & -1 & 1 & 0.0 & -1.4 & 1.42 \\
\hline 27 & 1 & -1 & 1 & 1 & -1 & 7.6 & 8.9 & -1.33 \\
\hline 28 & -1 & -1 & -1 & 1 & -1 & 0.0 & -0.8 & 0.81 \\
\hline 29 & 0 & 0 & -2 & 0 & 0 & 0.0 & -0.9 & 0.89 \\
\hline 30 & 0 & 0 & 0 & 0 & 0 & 16.0 & 15.7 & 0.26 \\
\hline 31 & 0 & -2 & 0 & 0 & 0 & 9.6 & 7.9 & 1.71 \\
\hline 32 & 0 & 0 & 0 & 0 & -2 & 13.3 & 12.3 & 0.96 \\
\hline
\end{tabular}

Note: ${ }^{a}$ Experiments 2, 4, 6, 8, 17 were five replications in the central point. ${ }^{\mathrm{b}}$ Observed value was the diameter of zones of inhibition; Candida vulgaris as the target microbe on PDA medium in 20-cm-diameter Petri dish was inoculated 24 hours at $30^{\circ} \mathrm{C}$. One dish: one replication, the data in the table were the average of three replications. $X_{1}=\mathrm{pH} ; X_{2}=$ Medium volume; $X_{3}=$ Rotary speed; $X_{4}=$ Temperature; $X_{5}=$ Inoculation volume.

The Student's $t$-test and $P$-values were used to check the significance of each coefficient; the results also indicated interaction strength between each independent variable. The results of the regression analysis were shown in Table 8. The degree of significance (Table 8) shows that the linear term regression coefficients of rotary speed were highly significant as demonstrated by the $P$-values $\left(P_{X_{3}}=.001\right)$. Initial $\mathrm{pH}$ and media volume were also significant at $5 \%$ level $\left(P_{X_{1}}=\right.$ .039, $\left.P_{X_{2}}=.020\right)$. Quadratic coefficients of primary $\mathrm{pH}$, media volume, rotary speed, and temperature were highly significant at $1 \%$ level, and showed negative effect on the antimicrobial activity.
This model resulted in ten 2D contour plots. The few response contour plots of the calculated model for antimicrobial activity were shown in Figures 3(a)-3(f) by keeping the other three variables constant at their middle level. The analysis of variance of regression for antimicrobial activity was summarized in Table 8. In the case of antimicrobial activity, this calculated model was able to explain $93.6 \%$ of the results (Table 9). The value of the adjusted determination coefficient (Adj $R^{2}=0.82$ ) was also very high to advocate for a high significance of the model [17]. The coefficient for quadratic effect of $\mathrm{pH}$, medium volume, temperature, and rotary speed may be significant to some extent. 


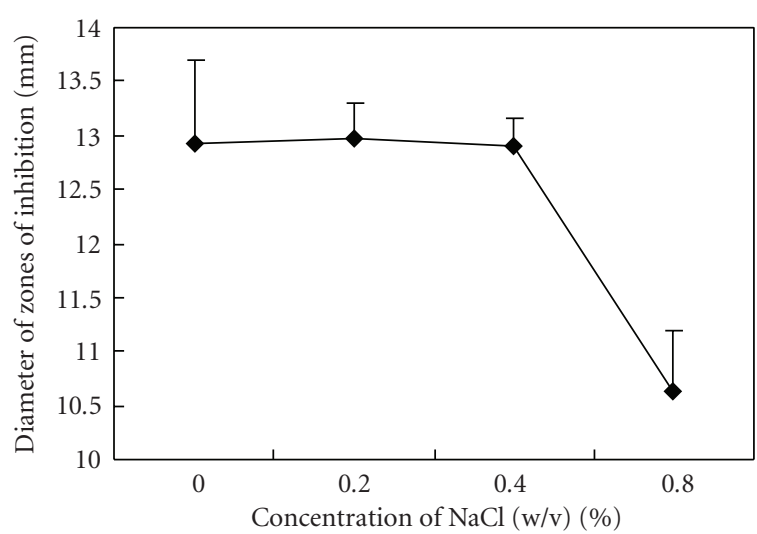

(a)

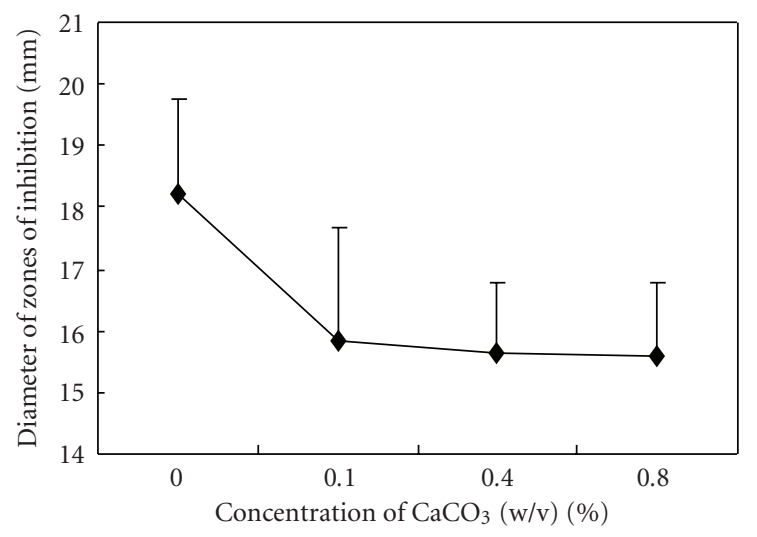

(c)

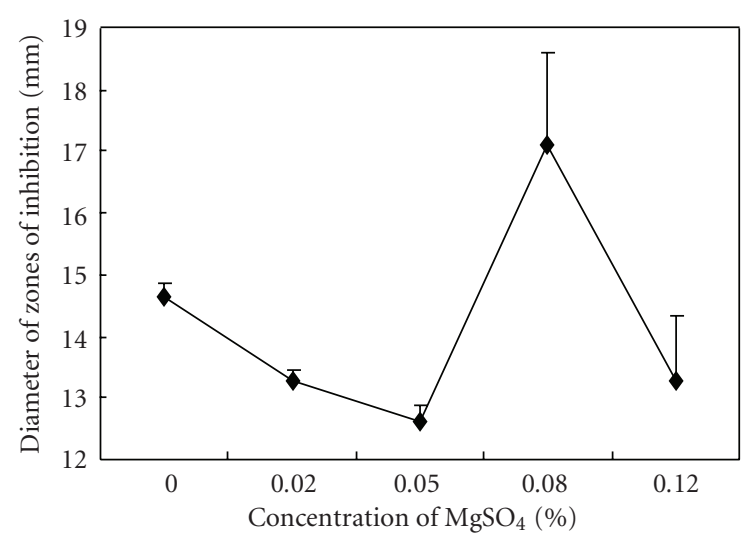

(b)

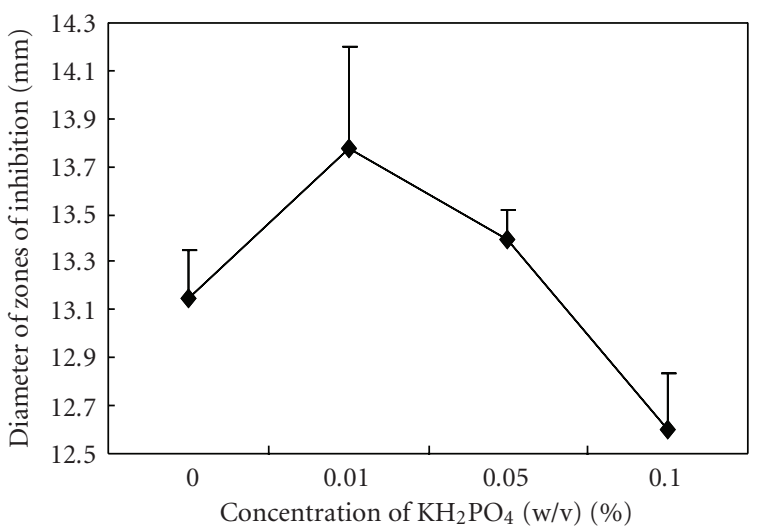

(d)

FiguRE 1: Effect of microelements at different concentrations on the production of antimicrobial active compounds in the fermentation supernatant of strain Hhs. $015^{\mathrm{T}}$ to Candida vulgaris on PDA. The antimicrobial activity was determined by measuring the translucent inhibition zones after incubating the dish 24 hours at $30^{\circ} \mathrm{C}$. Apple pomace $(1.5 \% \mathrm{w} / \mathrm{v})$ and rapeseed meal $(0.2 \% \mathrm{w} / \mathrm{v})$ were used as the carbon and nitrogen sources. (a)-(d) were $\mathrm{NaCl}, \mathrm{CaCO}_{3}, \mathrm{MgSO}_{4} \cdot 7 \mathrm{H}_{2} \mathrm{O}$, and $\mathrm{KH}_{2} \mathrm{PO}_{4}$, respectively.

The response surfaces 2D contour could be analyzed for determining the optimized value of the variables, but it was difficult to analyze all these simultaneously. Finally, the optimum culture condition was obtained as follows: initial $\mathrm{pH}=7.0$, medium volume $=90.0 \mathrm{~mL} / 250 \mathrm{~mL}$ plate, rotary speed $=100 \mathrm{rpm}$, temperature $=25.0^{\circ} \mathrm{C}$, and inoculation volume $=15.8 \%$.

These values predict a $17.5 \mathrm{~mm}$ growth inhibition zone caused by the antimicrobial activity. These optimized values of nutrient parameters were validated in a duplicate flask study and an average of $17.3 \pm 0.25 \mathrm{~mm}$ growth inhibition zone was obtained. This shows $98 \%$ validity of the predicted model. The result proved that the production of ingredients with antimicrobial activity had been improved by $20 \%$ when compared with the basal fermentation conditions (14.4 \pm $0.15 \mathrm{~mm}$ ) (Figures $2 \mathrm{~A}$ and B).

\section{Discussion}

Carbon sources could play an important role in the production of compounds with antimicrobial activity of strain Hhs. $015^{\mathrm{T}}$. Nutrition plays an important role in the onset and intensity of secondary metabolism, not only because of limiting the supply of an essential nutrient is an effective means of restricting growth but also because the choice of limiting nutrients can have specific metabolic and regulatory effects $[18,19]$.

The results of this study showed that production of compounds with antimicrobial activity was drastically reduced when a carbon source such as vinegar residue or no carbon source (black) was present in the culture medium. A similar catabolic repression mechanism for antibiotic production had been described for bacteria [20], suggesting that the synthesis of the antibiotic was related to phosphoenolpyruvate sugar phosphotransferase system, and controlling the concentration of carbon sources could regulate the synthesis of antibiotics. In the optimization of the culture medium, apple pomace was selected as the carbon source. Apple pomace, a by-product from a juice production factory in Qianxian, Shaanxi Province, contained numerous kinds of nutrients, such as proteins, fats, soluble sugars, $\mathrm{Ca}, \mathrm{P}$, and many other microelements, vitamins, and so forth [21].

For microbe growth and synthesis of the secondary metabolites, microelements (mineral and metal ions) 
TABLE 6: Analysis of the results of orthogonal design $\left(\mathrm{L}_{16} 4^{5}\right)$ for the optimization of strain Hhs. $015^{\mathrm{T}}$ alternative cultural medium.

\begin{tabular}{lccccc}
\hline Runs & $A$ & $B$ & $C$ & $D$ & $\begin{array}{c}\text { Diameter of zones } \\
\text { of inhibition }(\mathrm{mm})\end{array}$ \\
\hline 1 & 1.5 & 0.1 & 0.06 & 0.01 & 16.0 \\
2 & 1.5 & 0.2 & 0.07 & 0.02 & 15.6 \\
3 & 1.5 & 0.3 & 0.08 & 0.03 & 14.2 \\
4 & 1.5 & 0.4 & 0.09 & 0.04 & 15.0 \\
5 & 2.0 & 0.1 & 0.08 & 0.04 & 13.2 \\
6 & 2.0 & 0.2 & 0.09 & 0.03 & 14.8 \\
7 & 2.0 & 0.3 & 0.06 & 0.02 & 12.6 \\
8 & 2.0 & 0.4 & 0.07 & 0.01 & 15.9 \\
9 & 2.5 & 0.1 & 0.09 & 0.02 & 9.2 \\
10 & 2.5 & 0.2 & 0.08 & 0.01 & 9.9 \\
11 & 2.5 & 0.3 & 0.07 & 0.04 & 9.2 \\
12 & 2.5 & 0.4 & 0.06 & 0.03 & 15.1 \\
13 & 3.0 & 0.1 & 0.07 & 0.03 & 7.4 \\
14 & 3.0 & 0.2 & 0.06 & 0.04 & 16.0 \\
15 & 3.0 & 0.3 & 0.09 & 0.01 & 14.1 \\
16 & 3.0 & 0.4 & 0.08 & 0.02 & 9.9 \\
$X_{1}$ & 15.2 & 11.45 & 14.93 & 13.98 & \\
$X_{2}$ & 14.16 & 14.08 & 12.03 & 11.83 & \\
$X_{3}$ & 10.85 & 12.53 & 11.80 & 12.87 & \\
$X_{4}$ & 11.85 & 13.98 & 13.28 & 13.35 & \\
\hline$R$ & 4.35 & 2.63 & 3.13 & 2.15 & \\
\hline
\end{tabular}

Note: Candida vulgaris was used as the target microbe inoculated 24 hours at $30^{\circ} \mathrm{C}$ on PDA medium in $20-\mathrm{cm}$-diameter Petri dish. One dish: one replication, the data in the table were the average of three replications.

$A, B, C, D$ were apple pomace, rapeseed meal, $\mathrm{MgSO}_{4} \cdot 7 \mathrm{H}_{2} \mathrm{O}$, and $\mathrm{KH}_{2} \mathrm{PO}_{4}$, respectively. $\bar{X}_{i j}$ is the average value of the $j$ level of one variable in line $i$, and $R_{i}$ is the difference between the maximum and the minor average values of all of the levels of one variable in line $i$, roughly explaining the effect of every variable on the antimicrobial activity

$\bar{X}_{i j}=\sum X_{i j} / n ; n=4 ; j=1,2,3,4 ; R_{i}=\bar{X}_{i j \max }-\bar{X}_{i j \min } ; i=A, B, C, D$.

TABle 7: Analysis of variance of orthogonal design results for the optimization of strain Hhs. $015^{\mathrm{T}}$ alternative culture medium.

\begin{tabular}{lccccc}
\hline Variable & Parameter & $\mathrm{Seq} \mathrm{SS}^{\mathrm{a}}$ & $\mathrm{DF}^{\mathrm{b}}$ & $F$ & $F_{0.05}^{\mathrm{c}}$ \\
\hline$A$ & Apple pomace & 48.179 & 3 & 1.894 & 3.29 \\
$B$ & Rapeseed meal & 18.958 & 3 & 0.745 & 3.29 \\
$C$ & $\mathrm{MgSO}_{4} \cdot 7 \mathrm{H}_{2} \mathrm{O}$ & 24.725 & 3 & 0.972 & 3.29 \\
$D$ & $\mathrm{KH}_{2} \mathrm{PO}_{4}$ & 9.884 & 3 & 0.389 & 3.29 \\
Error & & 266.83 & 15 & & \\
\hline
\end{tabular}

Note: The data were analyzed using the software Oea-v31-p; $F<F_{0.05}$ showed that there was no significant difference in the concentration range of every variable. ${ }^{\mathrm{a}}$ Sum of squares; ${ }^{\mathrm{b}}$ Degree of freedom; ${ }^{\mathrm{c}} \mathrm{Critical}$ value when $P=.05$.

were necessary, which are an important part of enzyme reactive centers or could maintain the structure stability of biomacromolecules and the balance of cell osmotic pressure. For the secondary metabolites in Phoma sp., zinc, iron, and manganese were the most important

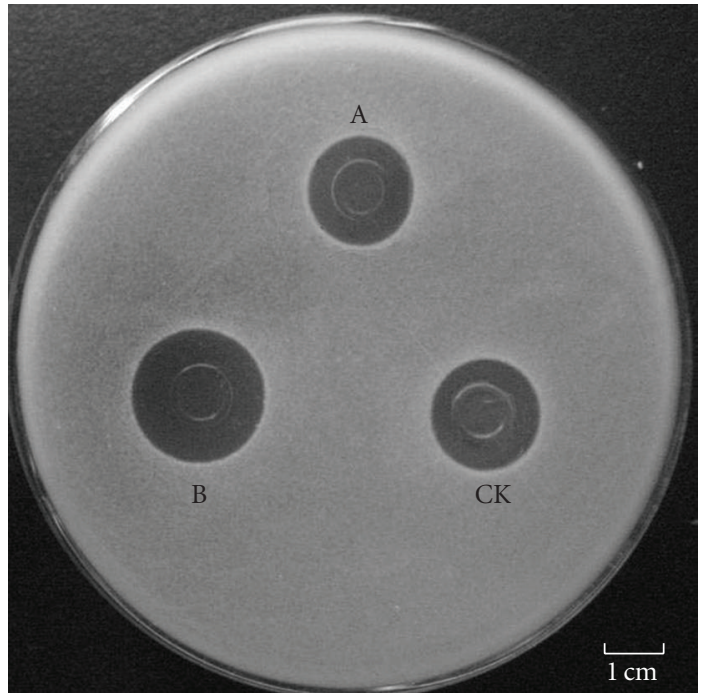

FIgURE 2: The antimicrobial activity in fermentation supernatants of strain Hhs. $015^{\mathrm{T}}$ to Candida vulgaris on PDA medium in 9$\mathrm{cm}$-diameter Petri dish. The antimicrobial activity was determined by measuring the translucent inhibition zones after incubating the dish 24 hours at $30^{\circ} \mathrm{C}$. A: alternative culture medium at basal fermentation condition; B: alternative culture medium at the optimal fermentation condition; CK: SSY medium at the basal fermentation condition.

trace elements [22]. Yang et al. [23] found that $\mathrm{MgSO}_{4}$, $\mathrm{MgCl}_{2}, \mathrm{NaCl}, \mathrm{KH}_{2} \mathrm{PO}_{4}, \mathrm{KNO}_{3}$, and $\left(\mathrm{NH}_{4}\right)_{2} \mathrm{SO}_{4}$ favored antibiotic production by Xenorhabdus spp. D43, but antibiotic production by addition of $\mathrm{Zn}\left(\mathrm{NO}_{3}\right)_{2}$ and $\mathrm{CuSO}_{4}$ decreased. In this experiment, the results showed that $0.06 \%$ $\mathrm{MgSO}_{4} \cdot 7 \mathrm{H}_{2} \mathrm{O}$ and $0.01 \% \mathrm{KH}_{2} \mathrm{PO}_{4}$ were proper for strain Hhs. $015^{\mathrm{T}}$ to produce antimicrobial activity. Increasing or reducing the concentrations of $\mathrm{MgSO}_{4} \cdot 7 \mathrm{H}_{2} \mathrm{O}$ and $\mathrm{KH}_{2} \mathrm{PO}_{4}$, the production of compounds with antimicrobial activity by strain Hhs. $015^{\mathrm{T}}$ decreased. Microelements at different concentrations showed different effects on the microbe physiological activity, so, the suitable concentrations are changing depending on microbe properties and fermentation medium [24].

The apple pomace and rapeseed meal were chosen as two main components in the optimum culture medium for their low market price, 598.4 RMB/t, while soybean in the SSY medium was $3774 \mathrm{RMB} / \mathrm{t}$ in the China market. Finally, the price of fermentation material for strain $\mathrm{Hhs} .015^{\mathrm{T}}$ was $0.1836 \mathrm{RMB} / \mathrm{L}$ in the optimum culture medium; $91.5 \%$ of the production cost were saved compared with the SSY medium, 2.1624 RMB/L, with similar antimicrobial activity. Hence, there are a high possibility and feasibility to use the modified cultural media in the scale-up fermentation of strain Hhs. $015^{\mathrm{T}}$.

In the optimization process of fermentation conditions, RSM proved to be a powerful tool. The approach allowed the determination of the culture conditions that yielded the highest antimicrobial activity by strain Hhs. $015^{\mathrm{T}}$. In this study, there was a mutual interaction between the medium volume and rotary speed (Figure $3(\mathrm{~d})$ ) to influence the 


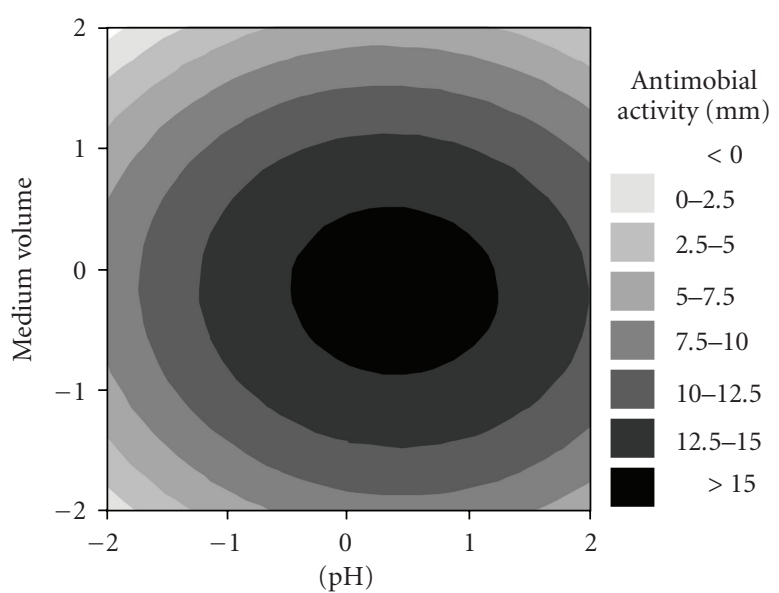

(a)

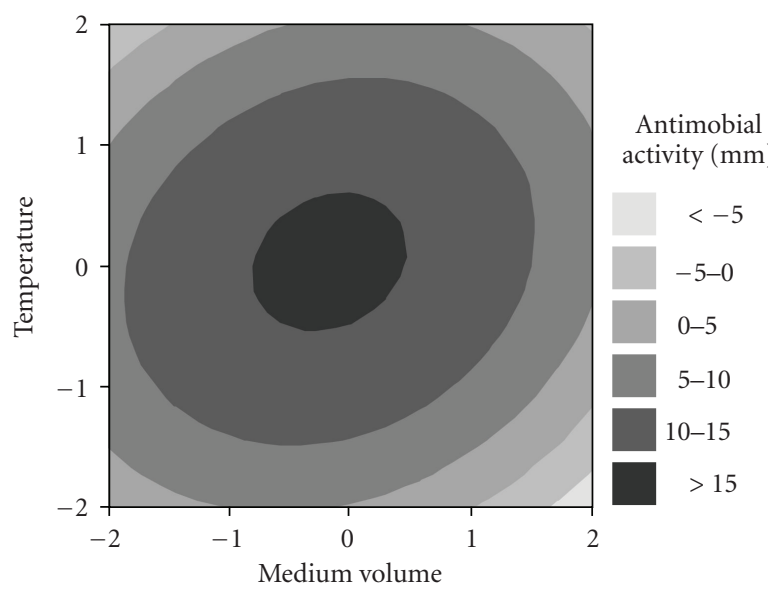

(c)

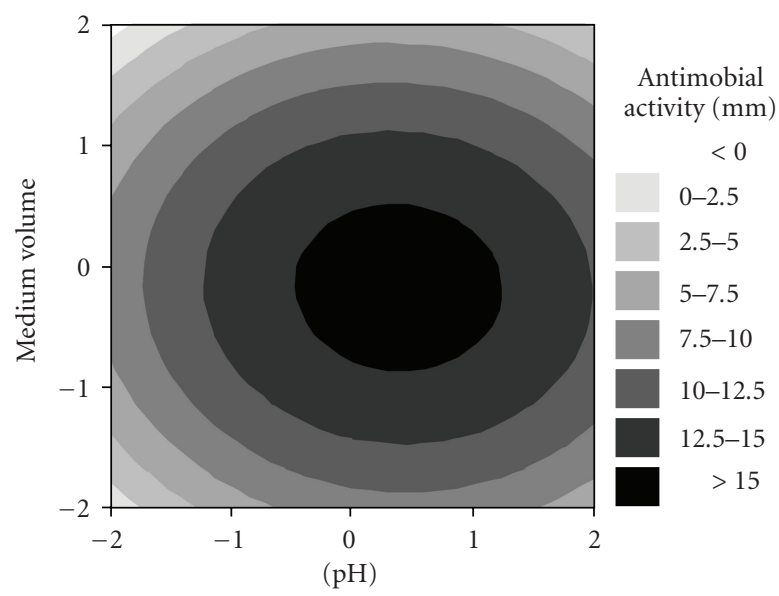

(e)

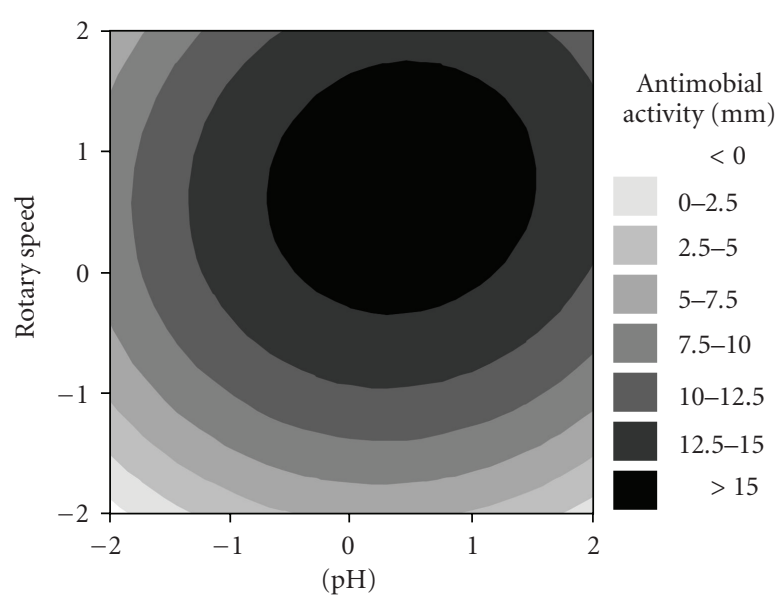

(b)

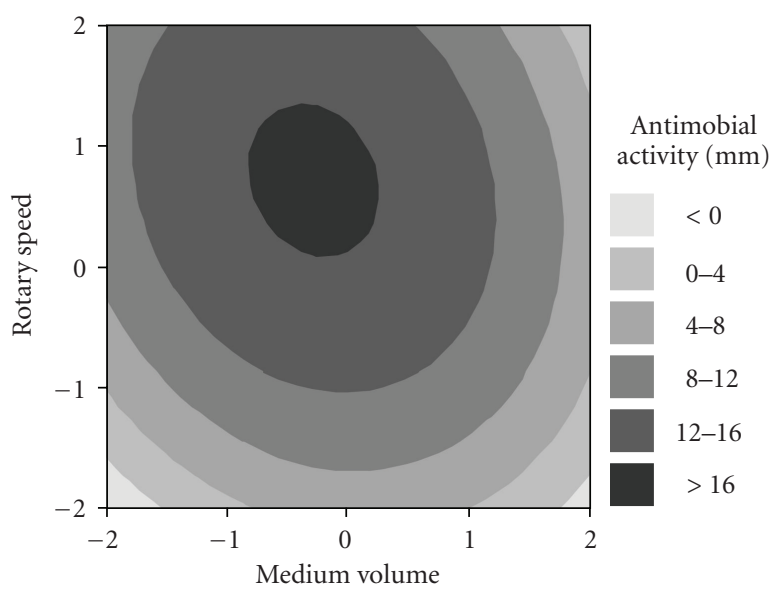

(d)

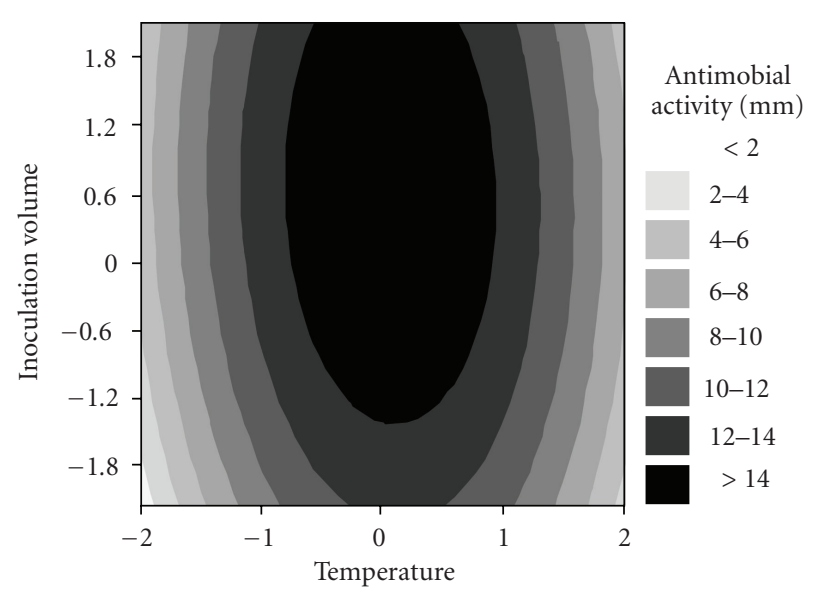

(f)

FIGURE 3: Contour plot of antimicrobial activity produced by strain Hhs. $015^{\mathrm{T}}(\mathrm{mm})$. (a): the effect of pH and medium volume on production of components with antimicrobial activity. (b): the effect of $\mathrm{pH}$ and rotary speed on synthesis of antimicrobial active compounds. (c): the effect of medium volume and temperature on production of antimicrobial active components. (d): the effect of medium volume and rotary speed on production of antimicrobial active compounds. (e): the effect of medium volume and inoculation volume on synthesis of antimicrobial active compounds. (f): the effect of temperature and inoculation volume on production of antimicrobial active components. Because a contour plot showed only two factors; the other factors were held constant at a middle level. The darkest area indicated the contour where the response is the highest. The range of $\mathrm{pH}$ was $-2(2.0),-1(4.5), 0(7.0), 1$ (9.5), $2(12)$. The range of medium volume (mL/250 mL) was $-2(30),-1(60), 0(90), 1(120), 2$ (150). The range of rotary speed (rev/min) was: $-2(0),-1(50), 0(100), 1(150)$, and $2(200)$. The range of temperature $\left({ }^{\circ} \mathrm{C}\right)$ was $-2(15),-1(20), 0(25), 1(30), 2(35)$. The range of inoculation volume (\%) was $-2(8),-1(11), 0(14), 1$ (17), and 2 (20). 
TABLE 8: Regression results from the data of central composite designed experiments of the optimization of strain Hhs. $015^{\mathrm{T}}$ fermentation conditions.

\begin{tabular}{lcccc}
\hline Term & Coef & SE-Coef & $T$ & $P$ \\
\hline$X_{0}$ & 15.74 & 1.20 & 13.15 & .000 \\
$X_{1}$ & 1.44 & 0.61 & 2.35 & $.039^{*}$ \\
$X_{2}$ & -1.66 & 0.61 & -2.71 & $.020^{*}$ \\
$X_{3}$ & 3.88 & 0.61 & 6.33 & $.000^{* *}$ \\
$X_{4}$ & 0.81 & 0.61 & 1.33 & .212 \\
$X_{5}$ & 0.64 & 0.61 & 1.04 & .321 \\
$X_{11}$ & -2.04 & 0.55 & -3.69 & $.004^{* *}$ \\
$X_{22}$ & -2.79 & 0.55 & -5.04 & $.000^{* *}$ \\
$X_{33}$ & -2.22 & 0.55 & -4.00 & $.002^{* *}$ \\
$X_{44}$ & -3.99 & 0.55 & -7.21 & $.000^{* *}$ \\
$X_{55}$ & -0.53 & 0.55 & -0.96 & .358 \\
$X_{12}$ & -0.11 & 0.75 & -0.14 & .890 \\
$X_{13}$ & 0.21 & 0.75 & 0.28 & .789 \\
$X_{14}$ & -0.72 & 0.75 & -0.96 & .359 \\
$X_{15}$ & 1.53 & 0.75 & 2.04 & .066 \\
$X_{23}$ & -1.29 & 0.75 & -1.72 & .113 \\
$X_{24}$ & 1.53 & 0.75 & 2.04 & .066 \\
$X_{25}$ & -0.72 & 0.75 & -0.96 & .359 \\
$X_{34}$ & 11.22 & 0.75 & 1.62 & .133 \\
$X_{35}$ & 0.82 & 0.75 & 1.09 & .299 \\
$X_{45}$ & -0.11 & 0.75 & -0.14 & .890 \\
\hline$N_{3} *$ & & &
\end{tabular}

Note: ${ }^{*}$ Significant at $5 \%$-level, ${ }^{* *}$ Significant at $1 \%$-level.

TABLE 9: Analysis of variance for the quadratic model.

\begin{tabular}{lccccc}
\hline Source & $\mathrm{DF}^{\mathrm{a}}$ & $\mathrm{SS}^{\mathrm{b}}$ & $\mathrm{MS}^{\mathrm{c}}$ & $F$ & $P$ \\
\hline Regression & 20 & 1448.98 & 72.449 & 8.04 & $.001^{*}$ \\
Linear & 5 & 502.68 & 100.535 & 11.15 & $.001^{*}$ \\
Square & 5 & 792.43 & 158.485 & 17.58 & $.000^{*}$ \\
Interaction & 10 & 153.88 & 15.388 & 1.71 & \\
Residual Error & 11 & 99.16 & 9.015 & & \\
Lack-of-Fit & 6 & 90.89 & 15.148 & 9.15 & \\
Pure Error & 5 & 8.27 & 1.655 & & \\
Total & 31 & 1639.91 & & & \\
\hline
\end{tabular}

Note: Coefficient of correlation $(R)=0.968$; Coefficient of determination $\left(R^{2}\right)=0.936$; adjusted $R^{2}=0.82$. ${ }^{*}$ Significant at $1 \%$-level; ${ }^{*}$ Degree of freedom; ${ }^{b}$ Sum of squares; ${ }^{c}$ Mean square.

production of antimicrobial active components. The optimal medium volume in the flask and the rotary speed were around $90 \mathrm{~mL}$ and $100 \mathrm{rpm}$, respectively. Our study revealed that rotary speeds, medium volume in the flask are related to the dissolved oxygen (DO) in shaken flasks [1]. A proper DO level was beneficial to antibiotic production, which is in agreement with those obtained in a 5 - $\mathrm{L}$ fermentor. Lai et al. [15] found that the shear effect on cell morphology such as mycelium growth or pellet formation was found closely influenced by the DO level and antibiotic production was maximized under suboptimal conditions for cell growth.
The analysis of significance of each coefficient of the quadratic regression model indicated that initial $\mathrm{pH}$ and temperature also have a significant effect on antimicrobial activity of strain $\mathrm{Hhs} .015^{\mathrm{T}}$. It could be observed that the antimicrobial activity increased upon increasing the initial $\mathrm{pH}$ from 2.0 to 7.0, but any further increase of $\mathrm{pH}$ resulted in decreased production of antimicrobial active components (Figures 3(a) and 3(b)). Therefore, the optimal primary $\mathrm{pH}$ was around 7.0. Similarly, the optimal temperature was around $25^{\circ} \mathrm{C}$, lower or higher temperatures reduced the production of compounds with antimicrobial activity (Figures 3(c), 3(e), and 3(f)). The results suggested that the broth $\mathrm{pH}$ could play a crucial role in the production of secondary metabolites; this finding is in good agreement with previous studies using for example Xenorhabdus species $[23,25,26]$. The authors suggested as possible reason that the key enzymes essential for synthesis of antibiotics become inactive at suboptimal $\mathrm{pH}$-values.

\section{Conclusions}

From the present study, the authors conclude that apple pomace and rapeseed meal were identified as the most suitable medium components for low-cost production of antimicrobial compounds by strain Hhs. $015^{\mathrm{T}}$. This is the first report about the fermentation of Saccharothrix actinomycete using apple pomace as the main medium component. Statistical optimization methods for fermentation process could overcome the limitations of classical empirical methods and proved to be a powerful tool for the optimization of conditions of production of antibiotics by strain Hhs. $015^{\mathrm{T}}$. The optimization of the fermentation process resulted not only in a $91.5 \%$ reduction of the costs of raw material compared to the conventional medium but also in a $20 \%$ higher antimicrobial activity. Furthermore, the information obtained is considered fundamental and useful for developing a cultivation process for efficient production of antibiotics on a large scale.

\section{Acknowledgment}

This work was supported by The Agricultural Program of Ministry of Agriculture (nyhyzx07-055, nyhyzx07-054), the Earmarked Fund for Modern Agroindustry Technology Research System (Apple Program), and The 111 Project (B07049).

\section{References}

[1] X. Yan, L. Huang, X. Wang, M. Yao, and Z. Kang, "Saccharothrix yanglingensis sp. Nov., an antagonistic endophytic actinomycete isolated from cucumber," submited to International Journal of Systematic and Evolutionary Microbiology.

[2] X. X. Wang, "Studies on indentificationm and optimization of fermentation of one plant endophytic actinomycetes strain Hhs.015 ${ }^{\mathrm{T}}$," Yang Ling: Northwest A\&F University, 2009.

[3] M. Yao, "Study on Endophytic Actinomycetes and Bioactive Substance Against Tomato Leaf Mould Pathogen," Yang Ling: Northwest A\&F University, 2007. 
[4] M. Yao, X. Tu, G. L. Huan, et al., "Screening of antagonistic endophytic actinomycetes against tomato pathogens and biocontrol effect on tomato leaf mould," Journal of Northwest A \& F University (Natural Science Edition), vol. 35, pp. 147150, 2007.

[5] Z. P. Gao, X. W. Ke, J. L. Wei, et al., "Biocontrol efficacy of apple tree valsa canker by endophytic actinomycetes," Acta Phytophylacica Sinica, vol. 5, pp. 410-416, 2009.

[6] S. Tsutomu, H. Fukushi, and S. Takeshi, "New alkaloid antibiotic tetrazomine areucture determination," The Journal of Antibiotics, vol. 44, pp. 1367-1370, 1991.

[7] A. Zitouni, H. Boudjella, F. Mathieu, N. Sabaou, and A. Lebrihi, "Mutactimycin PR, a new anthracycline antibiotic from saccharothrix sp. SA 103: I. Taxonomy, fermentation, isolation and bological activities," Journal of Antibiotics, vol. 57, no. 6, pp. 367-372, 2004.

[8] L. Lamari, A. Zitouni, T. Dob, et al., "New dithiolopyrrolone antibiotics from Saccharothrix sp. SA 233. II. Physicochemical properties and structure elucidation," Journal of Antibiotics, vol. 55, no. 8, pp. 702-706, 2002.

[9] K. S. Lam, J. Mattei, and S. Forenza, "Carbon catabolite regulation of rebeccamycin production in Saccharothrix aerocolonigenes," Journal of Industrial Microbiology, vol. 4, no. 2, pp. 105-108, 1989.

[10] R. P. John, K. M. Nampoothiri, and A. Pandey, "Fermentative production of lactic acid from biomass: an overview on process developments and future perspectives," Applied Microbiology and Biotechnology, vol. 74, no. 3, pp. 524-534, 2007.

[11] C. E. Voget, C. F. Mignone, and R. J. Ertola, "Butanol production from apple residue," Biotechnology Letters, vol. 7, pp. 43-46, 1985.

[12] N. Noro, Y. Sugano, and M. Shoda, "Utilization of the buffering capacity of corn steep liquor in bacterial cellulose production by Acetobacter xylinum," Applied Microbiology and Biotechnology, vol. 64, no. 2, pp. 199-205, 2004.

[13] Y. Zhang, Q. F. Meng, and W. X. Yang, "The medium of Streptomyces reseoflavus Men-myco-93-63," Journal of Agricultural University of HeBei, vol. 29, no. 2, pp. 77-82, 2006.

[14] A. Pandey, C. R. Soccol, P. Nigam, and V. T. Soccol, "Biotechnological potential of agro-industrial residues. I: sugarcane bagasse," Bioresource Technology, vol. 74, no. 1, pp. 69-80, 2000.

[15] L.-S. T. Lai, T.-H. Tsai, T. C. Wang, and T.-Y. Cheng, "The influence of culturing environments on lovastatin production by Aspergillus terreus in submerged cultures," Enzyme and Microbial Technology, vol. 36, no. 5-6, pp. 737-748, 2005.

[16] H. Hajjaj, P. Blanc, E. Groussac, J.-L. Uribelarrea, G. Goma, and P. Loubiere, "Kinetic analysis of red pigment and citrinin production by Monascus ruber as a function of organic acid accumulation," Enzyme and Microbial Technology, vol. 27, no. 8, pp. 619-625, 2000.

[17] A. I. Khuri and J. A. Cornell, Response Surfaces: Design and Analysis, Marcel Decker, New York, NY, USA, 1987.

[18] J. L. Doull and L. C. Vining, "Nutritional control of actinorhodin production by Streptomyces coelicolor A3(2): suppressive effects of nitrogen and phosphate," Applied Microbiology and Biotechnology, vol. 32, no. 4, pp. 449-454, 1990.

[19] M. Elibol, "Optimization of medium composition for actinorhodin production by Streptomyces coelicolor A3(2) with response surface methodology," Process Biochemistry, vol. 39, no. 9, pp. 1057-1062, 2004.
[20] M. H. Saier Jr., "Multiple mechanisms controlling carbon metabolism in bacteria," Biotechnology and Bioengineering, vol. 58, no. 2-3, pp. 170-174, 1998.

[21] Y. P. Ma, H. L. Ma, and J. Xu, “The research progress on apple pomace," Journal of Northwest Forestry University, vol. 21, no. 5, pp. 160-164, 2006.

[22] P. Roberto, A. David, and M. Naresh, "Medium optimization for the production of the secondary metabolite squalestatin S1 by a Phoma sp. combining orthogonal design and response surface methodology," Enzyme and Microbial Technology, vol. 37, pp. 704-711, 2005.

[23] X. F. Yang, D. W. Qiu, N. N. Jiao, Z. Liu., and J. J. Yuan, "Cultural medium and fermentation conditions of Xenorhabdus sp. strain D43," Chinese Journal of Biological Control, vol. 22, pp. 58-62, 2006.

[24] J. W. Cao and H. W. Ma, Microbial Engineering, Science Press, Beijing, China, 2002.

[25] B. Buckland, K. Gbewonyo, T. Hallada, L. Kaplan, and P. Masurekar, "Production of lovastatin, an inhibitor of cholesterol accumulation in humans," in Novel Microbials for Medicine and Agriculture, Elsevier Science, New York, NY, USA, 1989.

[26] X. F. Yang, H. W. Yang, H. Jian, and Z. Liu, "Effect of fermentation conditions on antibiotic production of Xenorhabdus nematophilus," Journal of Clinical Microbiology, vol. 28, no. 1, pp. 12-16, 2001. 

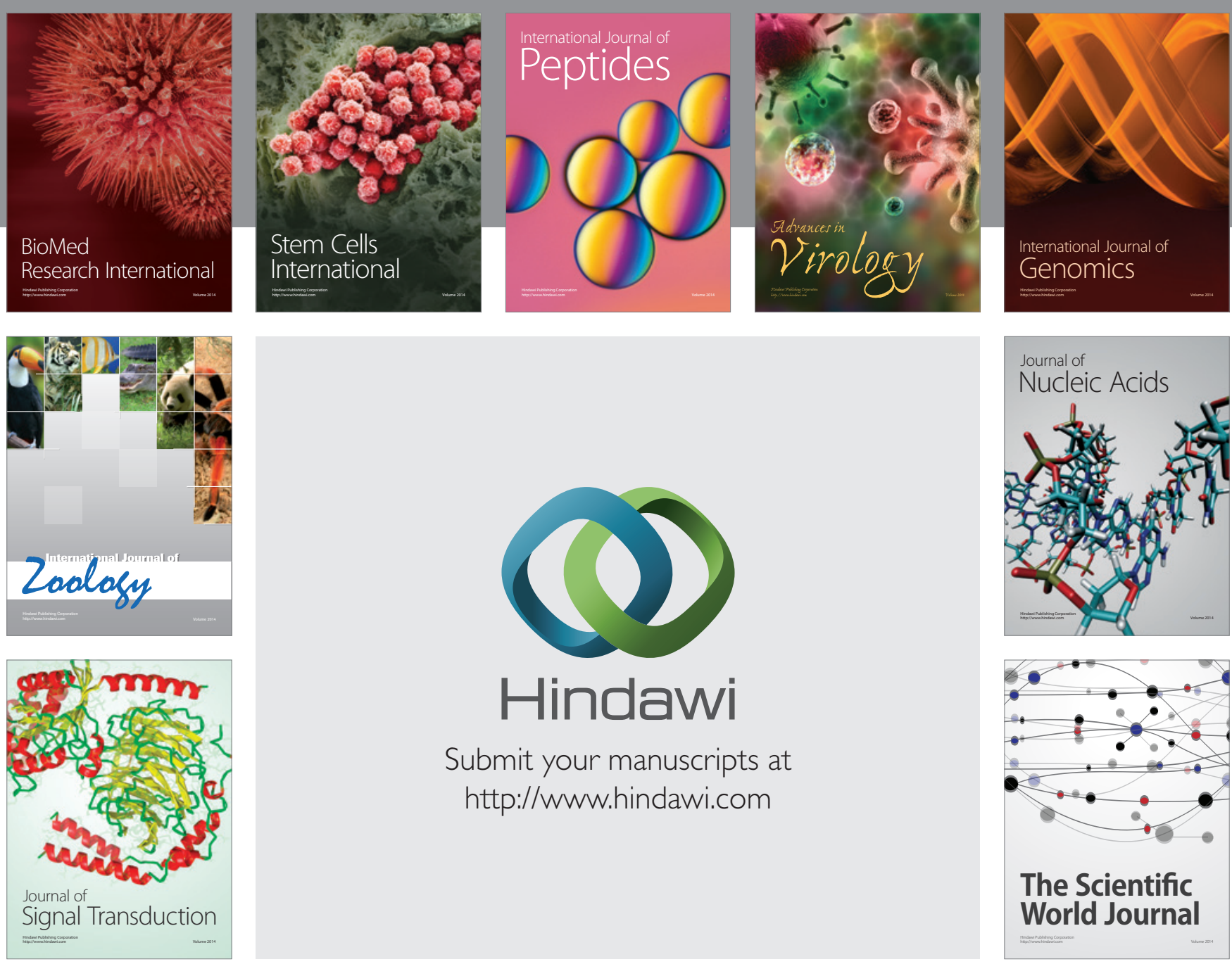

Submit your manuscripts at

http://www.hindawi.com
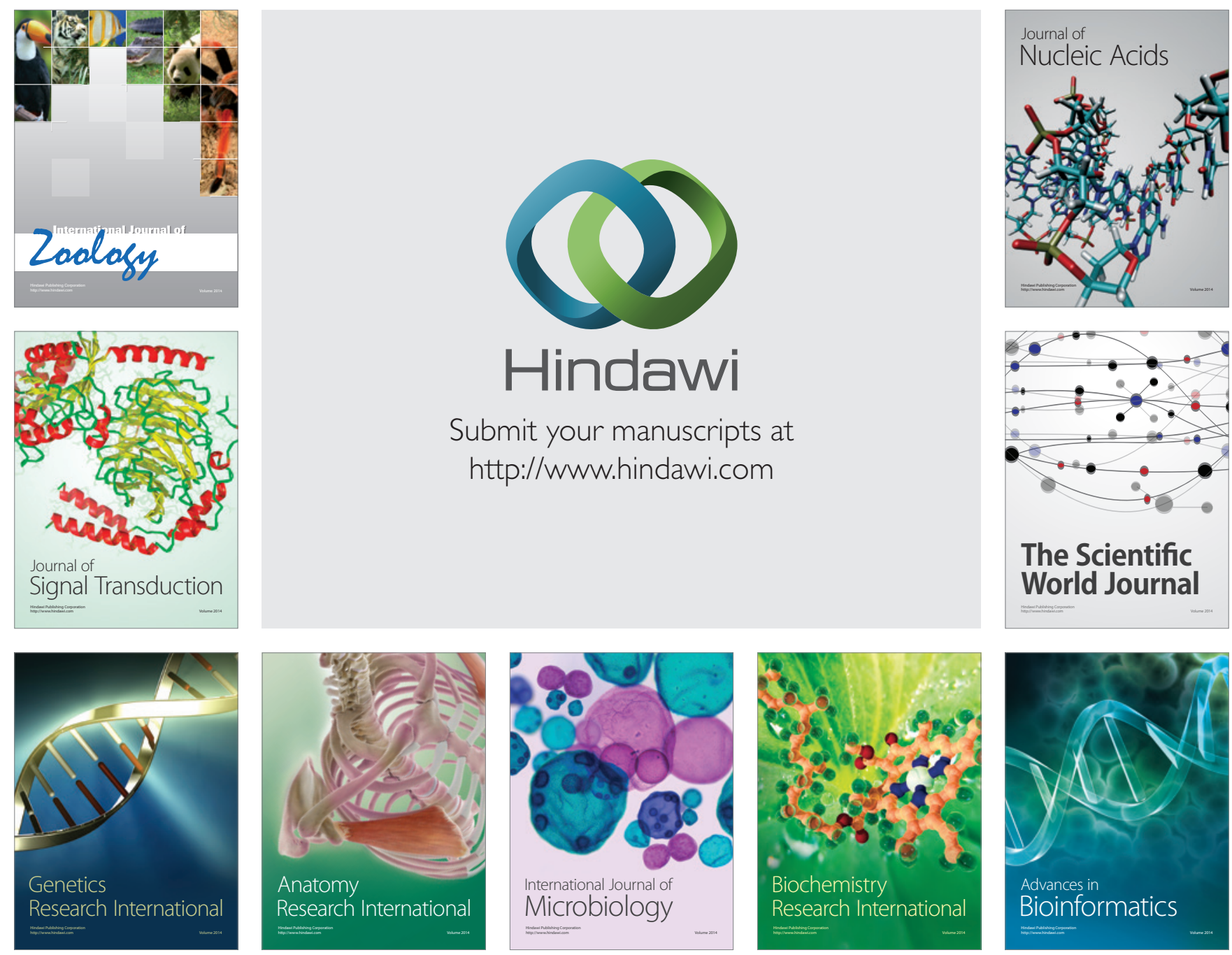

The Scientific World Journal
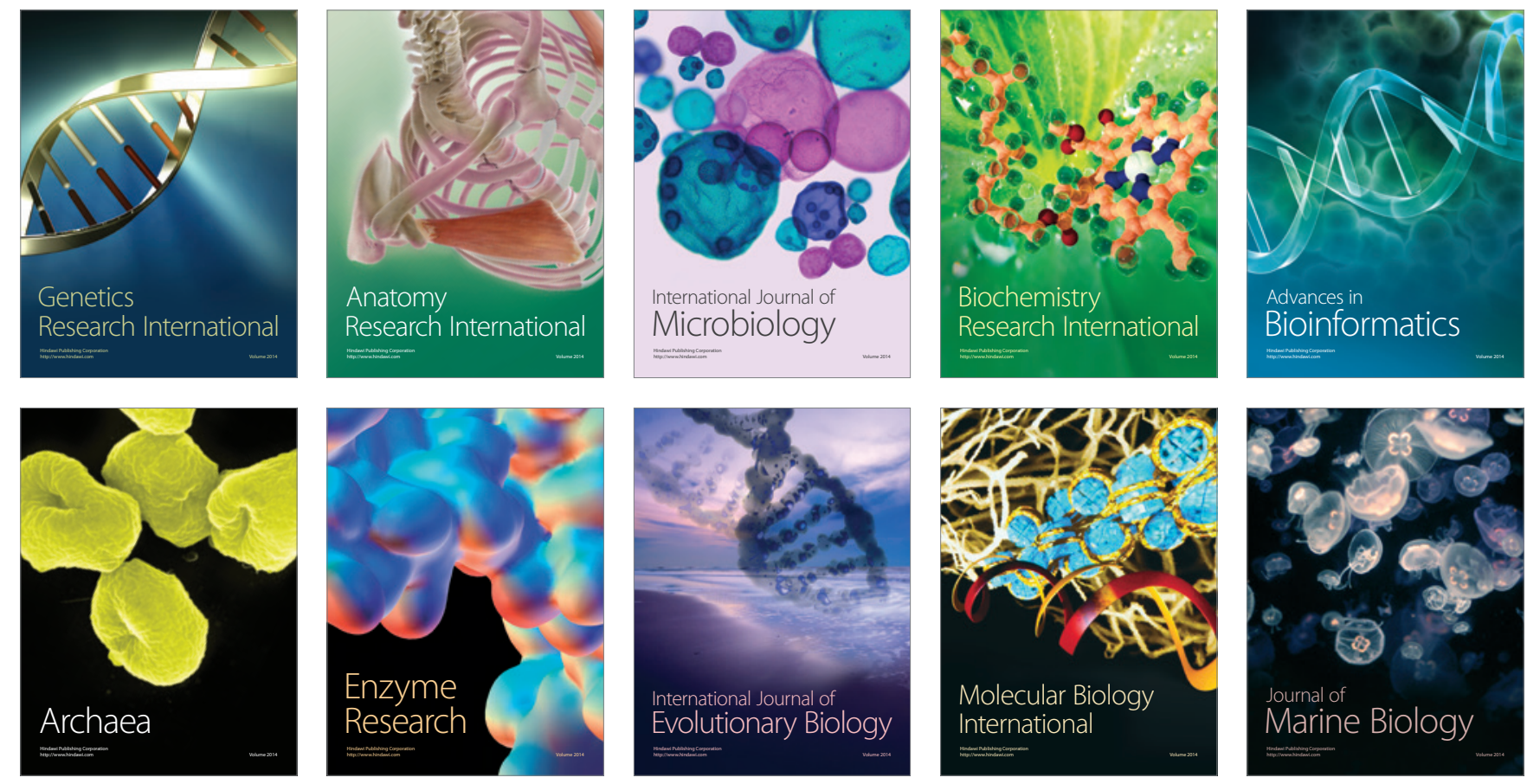